\title{
SLEEP POLYGRAPHIC PARAMETERS IN NEUROMUSCULAR DISEASES
}

\author{
MÁRCIA PRADELLA
}

SUMMARY - In a polysomnographic study of 32 neuromuscular patients - 22 with a form of muscular dystrophy, 3 with a form of congenital myopathy, 4 with a form of spinal muscular atrophy, 1 with a recurrent form of polymyositis and 1 with osteogenesis imperfecta syndrome - of which 21 were nonambulatory, we observed sleep related respiratory disturbances represented by: drops in oxygen saturation $(\mathrm{SaO} 2)$, cardiac arrythmia, sleep disruption, apneas, tachypnea, tachycardia and snoring. Nine out of the cohort of 32 patients presented with significant desaturations periods. These patients presented with an associated restrictive syndrome and thoracic deformities, some with tachypnea and/or $\mathrm{SaO} 2$ below $90 \%$ during wakefulness. In this group, snoring was observed in those patients with a form of muscular dystrophy while tachypnea was observed in patients who presented the highest desaturations levels. Sleep quantification revealed an increase of stage 1 sleep coupled with a decrease or even total absence of REM sleep. This is, we believe, a likely consequence of episodic desaturations that may accompany sleep hypoventilation which is potentialised during REM sleep stage.

KEY WORDS: polysomnography, neuromuscular diseases, sleep related respiratory disturbances.

\section{Parâmetros poligráficos do sono em doenças neuromusculares}

RESUMO - Estudando 32 pacientes com doenças neuromusculares -22 com forma de distrofia muscular, 3 com forma de miopatia congênita, 4 com forma de atrofia muscular espinal, 1 com forma recorrente de polimiosite e 1 com síndrome de osteogenesis imperfecta - dos quais 21 estavam impossibilitados de deambulação, distúrbios respiratórios relacionados ao sono foram observados sob forma dessaturação da oxi-hemogloblina, arritmia cardíaca, taquipnéia, taquicardia e roncos. Nove desses 32 pacientes apresentaram períodos de dessaturação de oxi-hemoglobina maiores que $4 \%$ em relação aos níveis obtidos em vigília e repouso. Esse grupo de pacientes era caracterizado por apresentar síndrome respiratória restritiva associada a deformidade torácica (principalmente escoliose). Alguns apresentaram taquipnéia e/ou saturação da oxi-hemoglobina abaixo de $90 \%$ durante o repouso e em vigilia. Neste grupo, roncos foram observados principalmente nos pacientes com forma de distrofia muscular, enquanto a taquipnéia foi observada sobretudo nos pacientes com os maiores níveis de dessaturação. A quantificação do sono mostrou aumento na porcentagem do estado 1 do sono associada a diminuição ou mesmo ausência do estado do sono paradoxal. Isso nos leva a crer em um provável mecanismo de proteção consequente à potencialização da hipoventilação observada durante o estado de sono paradoxal, em que os maiores níveis de dessaturação são observados.

PALAVRAS-CHAVE: polissonografia, doenças neuromusculares, distúrbios respiratórios relacionados ao sono.

Sleep, with REM sleep in particular, represents a critical stage in the maintenance of respiratory homeostasis in neuromuscular (NM) diseases. Sleep disordered breathing (SDB) may occur in a wide variety of these diseases (muscular dystrophies, congenital myopathies, etc) and may present with diverse, often isolated, symptoms or findings such as excessive daytime sleepiness, pulmonary

Sleep Laboratory and Pediatric Neurology Unit of the St Luc Training Hospital, Brussels, Belgium. Aceite: 5-maio-1994.

Dra. Marcia Pradella - Rua Antonio Rodrigues Passos 227, Jd. Cd Pirituba - 02941-040 São Paulo SP - Brasil. 
hypertension, congestive heart failure, morning headaches, orthopnea, snoring, or hypoxia induced nocturnal seizures ${ }^{19}$. Continuous and/or intermittent nocturnal positive pressure through the nose have been in use over recent years for the treatment of the hypoventilation associated to NM diseases, thus helping patients along the way to alter the natural evolution of their respiratory insufficiencies and to considerably increase their life expectancy even to the point of enhancing the quality of their life.

\section{MATERIAL AND METHODS}

1. Subjects. We performed polysomnographic recordings in $32 \mathrm{NM}$ patients in collaboration with the Pediatric Neurology Unit and the Sleep Laboratory of the St Luc Training Hospital attached to the Universite Catholique de Louvain (Belgium). The overwhelming majority of these patients were suggested to undergo this examination because of their complaints of a host of sleep related disturbances (SRD) i.e. snoring, morning headaches, daytime sleepiness and repeated respiratory infections associated to clinical deterioration especially highlighted by increased weakness and fatigue. These patients had previous diagnoses established by clinical and/or current assessment.

2. Recording procedures. The polysomnographic recordings were performed according to standard techniques ${ }^{27}$ : electroencephalogram (EEG), electrooculogram (EOG), electromyogram (EMG), electrocardiogram (ECG), oral and nasal airflow (thermocouples placed in front of mouth and nostrils), respiratory movements (strain gauge), breathing sounds, i.e., snoring (microphone attached to the skin over the larynx). These parameters were recorded on a polygraph at a paper speed of $10 \mathrm{~mm} / \mathrm{s}$.

The transcutaneous oxygen saturation ( $\mathrm{SaO} 2$ ) (Nellcor pulse oxymeter $\mathrm{N}-100$, Hayward, CA, USA) was likewise recorded. The mean of 10 measurements per second of $\mathrm{SaO} 2$ and pulse frequency (PF) from the oxymeter, along with the integrated signal from the microphone were stored in an intermediate data bank every 6 seconds. The file containing these measurements also held information on the exact time of the initial onset of the recording. This allowed us to correlate these data at a later stage along with other findings, namely data pertaining to vigilance stages and apneas.

The desaturation index (DI) was taken as the number of the desaturation episodes $\geq 4 \%$ expressed per hour of sleep. We considered a DI $<12$ as normal.

Sleep staging was performed according to standard methods in epochs of 60 seconds. Total sleep time (TST) was measured from the moment when the patient fell asleep until the final awakening, excluding wake time during sleep. The time of the various sleep stages was calculated as percentage of TST.

Movement arousal index (MA) was taken as the number of episodes showing increase in EMG accompanied by alpha rhythm in EEG for at least 2 seconds, during a sleep epoch, expressed per hour of sleep. We considered an MA $<20$ as being normal.

Snoring index (SI) was defined by the following equation:[(number of minutes with at least one snoring / total number of minutes) $x$ 100]. We considered a SI $\geq 40$ as significant.

Respiratory events lasting $\geq 9$ seconds were divided into hypopneas and apneas. We counted only the apneas. Apneas were classified as central (a simultaneous interruption of both air flow and thoracic/abdominal movements), obstructive (an interruption of air flow with persistent thoracic and/or abdominal movements) and mixed (the two phenomena are observed with a succession of central and obstructive apneas) ${ }^{14,18}$. A number of apneas $<10$ for the all night recordings was taken as normal.

Breathing frequency (BF) values were the minimum and maximum values counted during one minute in a stable period for each vigilancy state. Tachypnea was defined as BF higher or equal to 25 cycles per minute.

Pulmonary function tests evaluated by spirometry were contemporary to PSG recordings. Cardiac assessment was not however necessarily performed at the same time as these recordings.

3. Statistical analyses. A linear correlation was reached between the percent predicted values of the vital capacity (\% PVC) and the mean values for the following sleep parameters : SaO2, DI and PF. These variables were tested for TST, REM (rapid eye movement sleep) and NREM (non rapid eye movement sleep) sleep. 


\section{RESULTS}

The group studied (composed of 9 females and 23 males) was heterogeneous for several parameters. Ages ranged from 3 to 44 years. Twenty-one patients $(66 \%)$ were nonambulatory. Diagnoses were made in the usual way by clinical observation, enzymatic (CK), neurophysiologic (EMG), pathologic (biopsy) and genetic assessment.

Pulmonary function studies revealed that $19(68 \%)$ of the 28 patients who underwent spirometry studies had restrictive syndrome (Table 1). Transcutaneous $\mathrm{SaO} 2$ at rest and during wakefulness showed abnormal values (<93\%) in 6 patients (Patients 2, 21, 23, 25, 31 and 32). Cardiac evaluation highlighted specific (DMD

Table 1. Pulmonary function studies.

\begin{tabular}{|c|c|c|c|c|c|}
\hline $\mathrm{N}^{\circ}$ & VC (1) & $\%$ PVC & FEV1 (1) & PFEV1 & FEV1/VC (\%) \\
\hline 1 & 1.86 & 106 & 1.69 & 102 & 91 \\
\hline 2 & - & - & - & - & - \\
\hline 3 & 1.86 & 89 & 1.69 & 100 & 91 \\
\hline 4 & 2.14 & 99 & 1.78 & 100 & 83 \\
\hline 5 & 1.00 & 93 & 0.84 & 98 & 105 \\
\hline 6 & 1.87 & 101 & 1.46 & 96.5 & 95 \\
\hline 7 & 2.02 & 75.5 & 1.85 & 83.5 & 110 \\
\hline 8 & 0.73 & 28.5 & 0.65 & 30.5 & 107 \\
\hline 9 & 1.25 & 51 & 1.04 & 31 & 83 \\
\hline 10 & - & - & - & - & - \\
\hline 11 & 1.27 & 43 & 1.14 & 46 & 107 \\
\hline 12 & 0.55 & 29 & 0.48 & 31 & 105 \\
\hline 13 & 1.21 & 77 & 0.94 & 74 & 96 \\
\hline 14 & 1.64 & 33 & 1.41 & 34 & 104 \\
\hline 15 & 2.20 & 40 & 2.11 & 46.5 & 117 \\
\hline 16 & 2.65 & 65 & 2.43 & 73 & 92 \\
\hline 17 & 1.05 & 21.5 & 0.72 & 18 & 83.5 \\
\hline 18 & 5.25 & 101 & 4.27 & 101 & 100.5 \\
\hline 19 & 2.96 & 63 & 2.44 & 61 & 96 \\
\hline 20 & 0.26 & 25.5 & - & - & - \\
\hline 21 & - & - & - & - & - \\
\hline 22 & 0.38 & 9 & 0.31 & 10 & 108.5 \\
\hline 23 & 2.04 & 45.5 & 1.77 & 51.5 & 113 \\
\hline 24 & 0.45 & 21.5 & 0.40 & 23 & 106 \\
\hline 25 & 0.98 & 39 & 0.91 & 42 & 93 \\
\hline 26 & 1.01 & 34 & 1.03 & 38 & 102 \\
\hline 27 & - & - & - & - & - \\
\hline 28 & 0.6 & - & 0.6 & - & - \\
\hline 29 & 3.14 & 133.5 & 2.88 & 143.5 & 107 \\
\hline 30 & 3.48 & 85.5 & 3.25 & 99 & 117 \\
\hline 31 & 0.34 & 35.5 & 0.32 & 42.5 & 121 \\
\hline 32 & 0.31 & 50 & 0.26 & 54 & 84 \\
\hline
\end{tabular}

VC, vital capacity; \%PVC, percent predicted values for VC; FEV1, forced expiratory volume at one second; \%PFEV1, percent predicted values for FEV1.

Patients 2, 10 and 21 had mental disability, co-operation was not forthcoming or adequate; patient 27 was too young to co-operate on examination; patient 28 had VC and FEV1 below 0.61 . 
Table 2. SaO2 and DI for desaturating patients.

\begin{tabular}{ccccc}
\hline \multicolumn{4}{c}{ Nean SaO2 } & \multicolumn{2}{c}{ Minimum SaO2 } \\
& W & REM & REM & DI \\
\hline \hline 9 & 97 & 92 & 75 & - \\
10 & 96 & 92 & 86 & 60.0 \\
22 & 97 & 93 & 87 & 48.0 \\
23 & 93 & 82 & 46 & 47.4 \\
24 & 95 & 89 & 73 & 49.1 \\
25 & 81 & 27 & 20 & 95.8 \\
26 & 85 & 75 & 40 & 48.8 \\
31 & $<70$ & - & - & - \\
32 & 81 & 52 & 32 & 70.4 \\
\hline
\end{tabular}

and DMB patients) or aspecific changes in 22 of the 28 patients who underwent cardiac assessment. Scoliosis was present in 18 patients. The main associated clinical complaints were related to recurrent respiratory infections and/or snoring. Five patients presented epileptic seizures. Patient number 6 had von Willebrand type II disease.

Analysis of PSG data for $\mathrm{SaO} 2, \mathrm{DI}, \mathrm{HF}, \mathrm{MA}$, SI, apnea index and BF outlined that $56 \%$ (18) of our patients presented cardiac arrythmy during sleep; $16 \%$ (5) had sleep fragmentation (MA index $\geq 20$ ); $38 \%$ (12) had SI $\geq 40 ; 25 \%$ (8) had a number of apneas $\geq$ 10 and that $41 \%$ (13) were tachypneic (BF > $25 \mathrm{~min}$ 1). $\mathrm{SaO} 2$ dropped in $34.4 \%$ (11) of our patients with a desaturation percentage varying between 3 (Patient number 6 ) and 54 (Patient number 25). PF increased only slightly in $18.7 \%$ (5) of the patients. The DI was higher in 16 out of 29 patients (55\%) during REM sleep than in other vigilancy states.

PSG data for TST and percentage of sleep stages were compared with data taken from a review of current literature ${ }^{31}$, revealing that $64,5 \%$ (20) of our patients experienced a decrease in TST; $61,3 \%$ (19) had an increase in percent of stage 1 sleep and that $77,4 \%$ (24) experienced a reduction in percent of REM sleep.

Analysing these results we could distinguish a subgroup (Patients number 9, 10, 22, 23, 24, 25, 26, 31 and 32) of patients for whom the $\mathrm{SaO} 2$ desaturation was equal to or higher than $4 \%$ were we to compare the mean values observed during wakefulness and TST, NREM and REM sleep are compared. These desaturation periods occurred notably during REM sleep (Table 2). Five of these patients were nonambulatory, 8 underwent spirometry studies revealing a restrictive respiratory syndrome. Thoracic deformity and especially scoliosis were present in 7 patients (Table 3). Four showed sleep disruption, two with loud snoring and two with several periods of apnea. An abnormally high DI, cardiac arrythmia, and tachypnea were also observed in 7 of our subgroup (Table 4). Analysis of sleep quantification revealed that 5 patients had a decrease in TST, 7 showed an increased percentage of stage 1 sleep and that all had a drop in percentage of REM sleep (Table 5).

No real correlation was observed for the variables tested. Only the DI during REM sleep seemed slightly influenced by the \%PVC. The correlation coefficient between these variables was 0.046 .

Detailed tables with figures for all described variables may be consulted in the original work ${ }^{25}$ upon request.

Table 3. Pulmonary function ( $P F)$; thoracic deformity (TD); sleep related disturbances (SRD).

\begin{tabular}{ccll}
\hline N $^{\circ}$ & PF & TD & \multicolumn{1}{c}{ SRD } \\
\hline 9 & SRM & scoliosis & snoring \\
10 & $?$ & scoliosis & snoring \\
22 & SRS & $?$ & dyspnea \\
23 & SRM & $?$ & snoring, ri \\
24 & SRS & scoliosis & ri \\
25 & SRS & scoliosis & torpor \\
26 & SRS & scoliosis & ri \\
31 & SRS & funnel-shaped & ri, dyspnea \\
32 & SRM & scoliosis & sweating, weakness
\end{tabular}

SRM, moderate restrictive syndrome; SRS, severe restrictive syndrome; ri, recurrent respiratory infections. 
Table 4. PSG data.

\begin{tabular}{ccccccc}
\hline N $^{\circ}$ & MA & Snor & Apnea & BF & ARYT & PF \\
\hline 9 & - & - & 42 & - & yes & $<\mathrm{W}$ \\
10 & 41 & 68 & - & TW & no & $<\mathrm{W}$ \\
22 & - & - & - & TW & yes & $=\mathrm{W}$ \\
23 & 36 & 97 & 27 & - & yes & $<\mathrm{W}$ \\
24 & - & - & - & TWS & yes & $>$ W \\
25 & - & - & - & TWS & no & $>$ W \\
26 & 31 & - & - & TWS & yes & $=$ W \\
31 & +++ & - & - & TWS & yes & no REM \\
32 & - & - & - & TWS & yes & $<$ W \\
\hline
\end{tabular}

TW, tachypnea during wakefulness; TWS, tachypnea during wakefulness and sleep; PF, pulse frequency during sleep compared with wakefulness.

Table 5. TST and \% sleep stages.

\begin{tabular}{ccccccc}
\hline $\mathrm{N}^{\circ}$ & TST & $\% 1$ & $\% 2$ & $\% 3$ & $\% 4$ & $\%$ REM \\
\hline 9 & dec & inc & dec & inc & inc & dec \\
10 & dec & inc & inc & inc & dec & dec \\
22 & dec & inc & nl & nl & inc & dec \\
23 & nl & nl & nl & nl & nl & dec \\
24 & dec & inc & nl & inc & nl & dec \\
25 & nl & inc & $?$ & $?$ & inc & dec \\
26 & nl & inc & dec & inc & nl & dec \\
31 & dec & $?$ & $?$ & $?$ & $?$ & no \\
32 & nl & inc & nl & nl & nl & dec \\
\hline
\end{tabular}

The values were compared to data taken from literature [31]. dec, decreased values; inc, increased values; $\mathrm{nl}$, normal values; no, absence of sleep stage.

\section{COMMENTS}

Analysis of the results showed that sleep related respiratory disturbances (SRRD) occurred in a variable form and in different subjects given that $50 \%$ of these experienced drops in $\mathrm{SaO} 2 ; 56 \%$ had cardiac arrythmy; $16 \%$ presented increased number of arousals; $38 \%$ with snoring above $40 \%$ of their TST; apneas, especially of an obstructive type occurred in $25 \%$ of the studied cohort and increased BF was seen in $41 \%$. The DI augmented significantly during REM sleep in $55 \%$ while the PF rose in $18.7 \%$ of our patients. Sleep related complaints were present in all of the desaturating patients and were expressed principally by snoring and dyspnea. Recurrent respiratory infections which may be secondary to hypoventilation were also frequent in number.

A review of current literature on the topic highlights that in NM diseases, muscle weakness typically presents with a restrictive pattern on pulmonary function testing : markedly decreased vital capacity (VC) ( 40 to $70 \%$ of predicted value), reduced lung capacity and functional residual capacity and relatively normal residual volume and FEV1/VC (forced expiratory volume at one second / vital capacity) ratio. Diffusing capacity and gas-exchange are relatively normal. Many patients show a greater than expected loss in VC because of an associated decrease in the compliance of both the lungs and chest wall. The first is probably due to the presence of diffuse microatelectasis, the latter is due to the increased stiffness of the rib cage ${ }^{29}$. 
The breathing pattern in patients with respiratory muscle weakness is characterized by rapid shallow breaths and infrequent sighs. The volume and timing indices have not been adequately characterized. Tachypnea may be caused by afferent signals arising in the weakened respiratory muscles, intrapulmonary receptors stimulated by microatelectasis, or decreased respiratory compliance.

Pulmonary gas-exchange is usually well-maintained with a relatively normal alveolar-arterial oxygen tension gradient. An elevated $\mathrm{PaCO} 2$ becomes likely when respiratory muscle strength falls to $30 \%$ of the predicted normal value.

Acute respiratory failure producing respiratory acidosis may stem from a number of factors, including hypoventilation caused by decreased respiratory center output or respiratory muscle fatigue, impaired pulmonary gas-exchange, and excessive ventilatory requirements. Fatigue may impair ventilation by decreasing the contractile response to a given level of neuronal stimulation.

Respiratory failure is the major cause of death in patients with amyothrophic lateral sclerosis and in $75 \%$ of patients with Duchenne's dystrophy. Respiratory muscle weakness occurs early in the DMD but the diaphragm remains relatively spared, with the result that hypercapnia is uncommon except as a terminal event ${ }^{29}$. Patients with limb-girdle dystrophy experience early diaphragmatic involvement and may be prone to a higher frequency of hypercapnia.

In man respiratory function undergoes significant changes during sleep. Airway protective reflexes are altered, and stimuli that induce a cough during wakefulness may induce apnea during sleep. Sleep respiratory disturbances can be classified into two categories: those in which there is impairment of respiratory muscles or respiratory drive and those in which there is increased resistance to airflow in the upper airway. NM diseases can cause either or both of these abnormalities. The upper airway function may be altered by causing weakness of respiratory (diaphragm and muscles of the chest wall) and upper airway muscles or by altering muscle tone and coordination. Two principal abnormalities occur during sleep in patients with NM diseases: alveolar hypoventilation and sleep apnea, either obstructive or central.

An accurate accompaniment of the respiratory function in neuromuscular patients is of paramount importance. It is known that a decrease of $5 \%$ in absolute values of the VC in a year frequently occurs during the terminal phase of Duchenne's muscular dystrophy. Heckmatt et al. ${ }^{17}$ observed that when the VC fell below $700 \mathrm{ml}$ the risk of death was high and clinical signs of hypoventilation appeared. Given that ventilatory disturbances are potentialized or worsened during sleep, some precautionary measures are required such as transcutaneous oxymetry or, even better, PSG recordings with the aim of analysing if periods of desaturations arise during sleep.

The occurence of a restrictive syndrome was present in all of the 8 desaturating patients who underwent spirometry studies. Their VC values comprised between 9 and $51 \%$ of the predicted values for subjects with corresponding sex, age, weight and height. BF had already increased in 7 out of the 9 desaturating patients during wakefulness.

Eighteen patients suffered from scoliosis. This may be associated to the evolutivity of neuromuscular diseases coupled with the onset of the ageing process. Taken as fact that patients with scoliosis from any cause often present hypoventilation during sleep, and particularly during REM sleep, caused principally by reduced chest wall movement, the presence of scoliosis may be considered as a contributing factor in the development of desaturation periods during sleep.

In relation to sleep quantification changes, the observed increase in percentage of stage 1 sleep coupled with a drop or even total absence of REM sleep encouraged us to correlate this with the same changes observed in sleep apnea-hypopnea syndrome. In this syndrome the phenomenon may be viewed as a protective reaction possibly due to the fact that it is during REM sleep that the 
largest amount of apneas, particularly obstructive in nature, occur. In our cohort, higher desaturation levels were also present particularly during REM sleep.

As far as we are aware this has been the first report of the observation of snoring in NM patients. In our group of 32 patients, only 6 presented with absence or with a very slight (during 1 to $2 \%$ of the TST) snoring recording. The other $26(81 \%)$ snored between 6 and up to $97 \%$ of their TST. Sleep disruption represented by an elevated number of movement arousals (MA) was observed in 5 patients (Patients 3, 10, 19, 23, 26). All of these presented frequent snoring. These patients however never complained of daytime sleepiness. Snoring was frequently, but not always, associated to apneas. Out of the 9 desaturating patients, 6 snored (Patients 9, 10, 22, 23, 26 and 32). Of these, only Patients 9 and 23 had apneas. Sleep disruption was present in patients 10, 23 and 26. None of these desaturating patients suffered from obesity. This encouraged us to concur with Aldrich' ${ }^{1}$ premiss that snoring in NM patients is produced by loss of tone and strength in pharyngeal musculature rather than by fatty tissue accumulation in this region as may be observed in loud snorers with sleep apnea-hypopnea syndrome. We believe that snoring could worsen the already dangerous effect of sleep and principally REM sleep hypoventilation, as observed in patients 10, 22, 26 and 32 who did not present associated apneas.

Conclusion. The problems resulting from the interaction of normal sleep physiology and respiratory muscle weakness are most often seen in patients with Duchenne's muscular dystrophy owing to the frequency of this disease. The generalized respiratory muscle weakness of this and many other chronic myopathies arises in parallel with progressive immobility. Scoliosis is frequently associated but respiratory symptoms are often a pre-terminal feature, when hypoxaemia may serve as an important marker of vulnerability to minor intercurrent insults such as respiratory infection ${ }^{28}$.

However other NM diseases such as lower motor neurone and muscle diseases may present ventilatory deficiencies. Conditions characterized by selective deficits in diaphragm function, such as acid maltase deficiency or those which may compromise this muscle in a more extensive way as in limb-girdle dystrophy, myotonic dystrophy or congenital muscular dystrophies, may present with nocturnal and/or supine breathlessness well before their limb weakness is symptomatic. Mitochondrial encephalomyopathies may be complicated by disordered central ventilatory drive leading to sleep related respiratory disturbances. All of these ventilatory deficits are likely to be potentiated by sleep.

Our study did not allow for the observation of important differences between the NM diseases studied. Frequently we opted for the individual analysis rather than analysing groups of NM diseases. We feel that our contribution to the discrimination of SRRD and especially the observation of sleep quantification changes and snoring may be helpful to our understanding of the symptoms presented by NM patients and may be useful for clinical practice when unadorned questions such as: How well do you sleep? or Do you snore? may give us some indications as to episodic desaturations which more than likely accompany hypoventilation during sleep and especially REM sleep.These are basic questions underscoring a grimmer reality.

Treatment by using nasal ventilation is principally aimed at patients with disabling symptoms of dyspnea, fatigue, increased weakness, diurnal somnolence or recurrent respiratory infections due to a poor ventilation. Respiratory management of those with asymptomatic sleep hypoxemia remains open to discussion.

Acknowledgements - Our deepest appreciation goes to Prof. G Aubert, director of the Sleep laboratory, St Luc's training Hospital, Brussels, Belgium where the bulk of this research was carried out. Sincerest thanks to Prof. G Ferrière of the Pediatric Neurology Unit for academic and technical skills provided.

\section{REFERENCES}

1. Aldrich MS. Neurologic aspects of sleep apnea and related respiratory disturbances. Otolaryngol Clin North Am 1990, 23: 761-769.

2. American Thoracic Society. Indications and standards for cardiopulmonary sleep studies. Am Rev Resp Dis 1989, 139: 559-568. 
3. Back JR, Campagnolo DI, Hoeman S. Life satisfaction of individuals with Duchenne muscular dystrophy using long-term mechanical ventilatory support. Am J Phys Med Rehabil 1991, 70: 129-135.

4. Baydur A, Gilgoff I, Prentice W, Carlson M, Fischer A. Decline in respiratory function and experience with long-term assisted ventilation in advanced Duchenne's muscular dystrophy. Chest 1990, 97: 884-889.

5. Bertrand A, Milane J, Jonquet $O$, Bertrand P. De la poliomyélite antérieure aiguë aux myopathies: prise en charge de l'insuffisance respiratoire chronique par déficit neuromusculaire. Bull Acad Natle Méd 1989, 173: 769-776.

6. Bye PTP, Ellis ER, Donnelly PD, Issa FG, Sullivan CE. Role of sleep in the development of respiratory failure in neuromucular disease. Am Rev Respir Dis 1985, 131: A108.

7. Carrol N, Bain RJ, Smith PEM, Saltissi E, Edwards RHT, Calverley PMA. Domiciliary investigation of sleep-related hypoxaemia in Duchenne muscular dystrophy. Eur Respir J 1991, 4: 434-440.

8. De Troyer A, Borenstein S, Cordier R. Analysis of lung volume restriction in patients with respiratory muscle weakness. Thorax 1980, 35: 603-610.

9. Delguste P, Rodenstein DO. Désaturations nocturnes dans la myopathie de Duchenne de Boulogne. Entretiens de la Fondation Garches 1990, 263-264.

10. Delmas MC,Bérard C. Prise en charge globale de l'amyotrophie spinale infantile: guide practique pour les équipes médicales. Pédiatrie 1990, 457-464.

11. Douglas NJ. Control of breathing during sleep. Clin Sci 1984, 67: 465-472.

12. Duron B. Respiration et sommeil. Association des Physiologistes 1987, A57-A71.

13. Estournet B, Bataille J, Commare MC, Urtizberea JA, Barois A. La ventilation nasale chez l'enfant atteint de maladie neuro-musculaire. Entretiens de la Fondation Garches 1990, 273.

14. Gastaut H, Duron B, Papy JJ, Tassinari CA, Waltregny J. Etude polygraphique comparative du cycle nycthómérique chez les narcoléptiques, les pickwickiens, les obèses et les insuffisants respiratoires. Rev Neurol 1966, 115:456-462.

15. Guilleminault C. The role of sleep and sleep states on breathing disorders. Schweiz Med Wschr 1988, 118: 1331-1332.

16. Heckmatt JZ. Respiratory care in muscular dystrophy. Br Med J 1987, 295: 1014-1015.

17. Heckmatt JZ, Loh L, Dubowits V. Nocturnal hypoventilation in children with nonprogressive neuromuscular disease. Pediatrics 1989, 83: 250-255.

18. Krieger J, Turlot JC, Mangin P,Kurtz D. Breathing during sleep in normal young and elderly subjects : hypopneas, apneas and correlated factors. Sleep 1983, 6: 108-120.

19. Kryger MH, Steljes DG, Yee WC, Mate E, Smith SA, Mahowald M. Central sleep apnoea in congenital muscular dystrophy. J Neurol Neurosurg Psychiatry 1991, 54: 710-712.

20. Le Balle F, Quera-Salva MA, McCann C, Barbe F, Lattre J, Gajdos P, Troche G. Apnées du sommeil chez les patients atteints de dystrophie musculaire de Duchenne de Boulogne. 1990, 265-266.

21. Lugaresi E, Cirignotta F, Montagna P. Snoring: pathogenic, clinical and therapeutic aspects. In Kryger M, Roth T, Dement WC (eds). Principles and practice of sleep medicine. Philadelphia, W B Saunders Company 1989, 494-500.

22. Manni R, Zucca C, Galimgerti CA, Ottolini A, Cerveri I, Bruschi C, Tartara A. Nocturnal sleep and oxygen balance in Duchenne muscular dystrophy. Eur Arch Psychiatry Clin Neurosci 1991, 240: 255-257.

23. Miller RG, Chalmers AC, Dao H, Filler-Katz A, Holman D, Bost F. The effect of spine fusion on respiratory function in Duchenne muscular dystrophy. Neurology 1991, 41: 38-40.

24. Newson-Davis JM, Goldman M, Loh LC. Diaphragm function and alveolar hypoventilation. Q J Med 1976, 177: 87-100.

25. Pradella M. A study of oxygen saturation and other polygraphic parameters in neuromuscular diseases with particular reference to muscular dystrophies. Master of Biomedical Science (Thesis), Université Catholique de Louvain (Belgium). Lowain, 1993.

26. Raphael JC, Bouvet $\mathrm{F}$, Chevret $\mathrm{S}$. Evaluation des différents moyens de ventilation mécanique à domicile dans la dystrophie musculaire de Duchenne de Boulogne: résultats intermédiares d'une étude prospective multicentrique. Entretiens de la Fondation Garches 1990, 259-260.

27. Rechtschaffen A, Kales A. A manual of standardized terminology, techniques and scoring system for sleep stages of human sugjects. Los Angeles: UCLA, 1968.

28. Smith PEM, Edwards RHT, Calverley PMA. Mechanisms of sleep-disordered breathing in chronic neuromuscular disease: implications for management. Q J Med 1991, 296: 961-973.

29. Tobin MJ. Respiratory muscles in disease. Clin Chest Med 1988, 9: 263-286.

30. Vignos PJ, Spencer GE Jr, Archibald KC. Management of progressive muscular dystrophy of childhood. JAMA 1963, 184: 103-110.

31. Williams RL, Karacan I, Hursch CJ. Electroencephalography of human sleep: clinical applications. New York: John Wiley \& Sons, 1974. 